
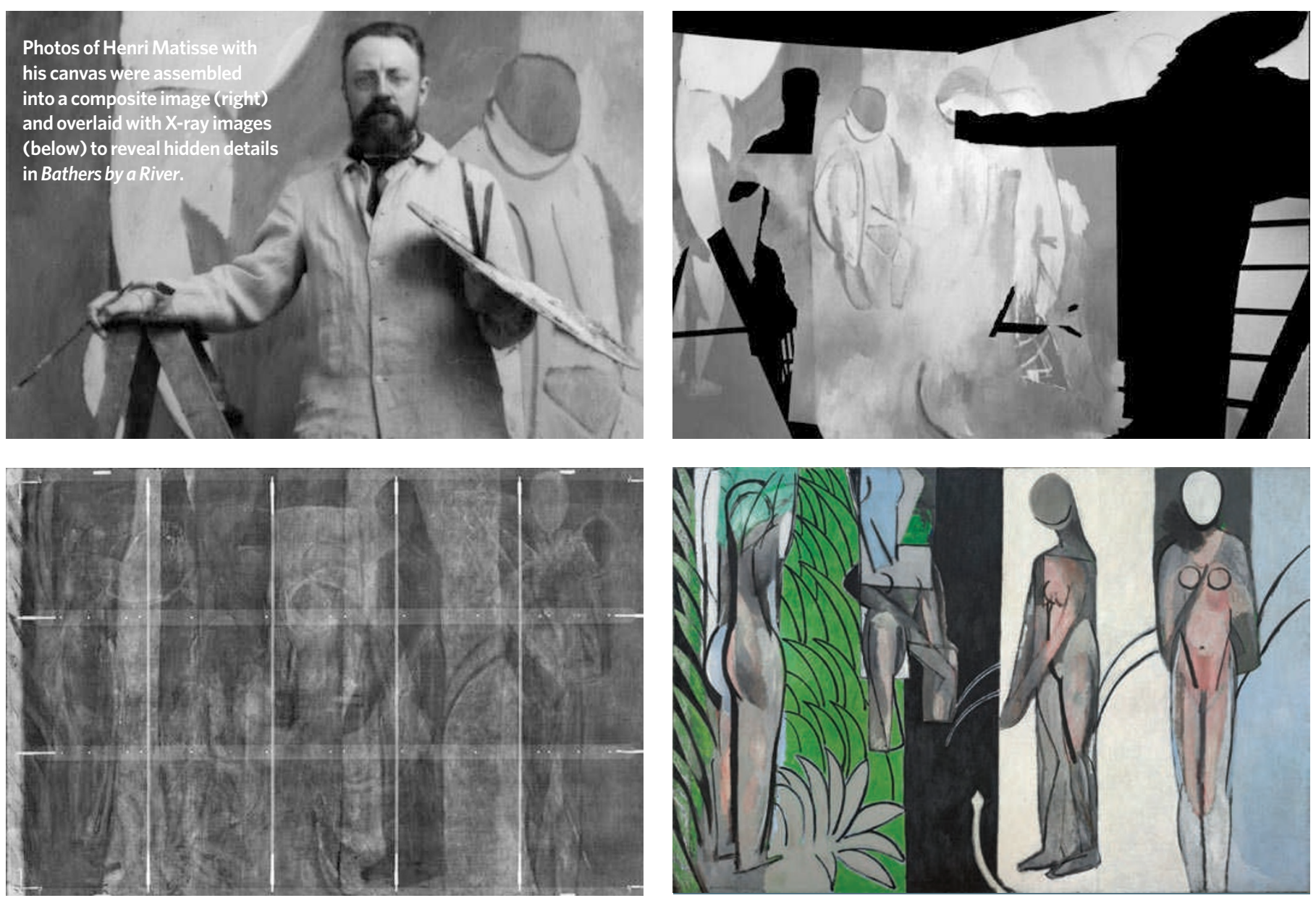

\title{
Matisse's methods revealed
}

\author{
Matisse: Radical Invention, 1913-1917 \\ The Art Institute of Chicago \\ Until 20 June
}

In 1913 the French artist Henri Matisse embarked on a period of restless experimentation, eschewing the rich colours and sinuous lines of his earlier works for a more abstract, geometric approach to painting, dominated by blacks and greys. He reworked his paintings again and again, scraping at the paint as if it were plaster and carving it like wax. An exhibition running until June at the Art Institute of Chicago, Illinois, analyses the evolution of these artworks using scientific methods to 'digitally peel away' many stages of the artist's compositions.

Matisse: Radical Invention includes more than 125 paintings, sculptures and drawings. It highlights two that the artist considered among his most pivotal: Bathers by a River (pictured, bottom right) and the series of bronze bas-reliefs titled Back (1-4). Bathers, which he painted in stages from 1909 to 1917, began as a pastoral scene depicting five nude women beside a waterfall. Matisse later removed one of the figures and transformed the others into sombre, abstract forms, isolating each one against columns of green, black, white and grey-blue, and turning a blue stream into a black band. To show how Matisse altered the painting over time, conservators at the institute combined various digital images of the work produced from infrared reflectograms, scanned X-radiographs and early photographs.

$\mathrm{X}$-rays reveal paint layers of different thicknesses and pigments of different atomic weight. $\mathrm{X}$-raying of the nearly four-metre-wide Bathers canvas in the 1970 s generated 122 separate $\mathrm{X}$-ray films, or tiles. But pasting these together left gaps and distortions due to misalignments of the scanning beam. Using custom software created by mathematician Robert Erdmann of the University of Arizona in Tucson, the conservators have adjusted for these distortions and matched the separate tiles seamlessly. "It was only in the distortion-free image that we were able to pick out certain subtle details, such as the diagonal edges of the riverbank that are part of the earliest painted state," explains conservator Kristin Lister.

In producing the infrared reflectograms, light of wavelengths between 750 and 3,000 nanometres penetrates the upper layers of paint to

reach lower layers that contain infrared-absorbing media, such as charcoal, revealing sketches that are normally hidden below the surface.

The team also analysed historical photographs of Matisse taken while he was painting Bathers. In these, the painting is in the background at an oblique angle, partially obscured by the artist (pictured, top left). Erdmann wrote software to infer the positions and orientations of the camera relative to the painting in each of these photographs, and then reconstructed an image of the painting as seen from the front (pictured, top right). Conservators then overlaid the $\mathrm{X}$-ray images (pictured, bottom left) and infrared reflectograms with composites of the historical pho-

"Insights into Matisse's
working methods show
how science can transform
our understanding of art."

Laser-imaging technology has also revealed information about Backs, a series of four monumental bronzes of female nudes, sculpted between 1909 and 1930. Matisse fashioned each new Back from a plaster cast of the previous one, adding or removing plaster to gradually transform the curving naturalism of the first Back into a more simplified, stocky form. Three-dimensional digital models created by 


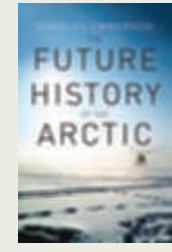

As global natural resources dwindle and Earth warms, the Arctic is set to become a geopolitical stage. In The Future History of the Arctic (PublicAffairs, 2010),

Charles Emmerson, a writer and global-risk specialist, explains how the region's oil and mineral wealth is being eyed by surrounding nations. He reveals the forces that will shape the Arctic this century, looking at its history and landscape, from polar expeditions and Russian gulags to oilindustry sprawl. Emmerson's analysis comes on the heels of two other recent books by writers who travelled across the Arctic to witness the region's development - Alun Anderson's After the Ice (HarperCollins, 2009) and Sara Wheeler's The Magnetic North (Jonathan Cape, 2009).

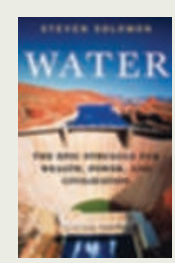

Water is becoming scarce. In Water (HarperCollins, 2010), journalist Steven Solomon offers a sweeping history of civilization's struggle to obtain and manage water supplies. His synthesis examines trends caused by climate change including melting glaciers, flooding and drought; social divisions between those who have access to water and those who do not; how water is key to national security; and how it has played a part in the rise and fall of great powers through history.

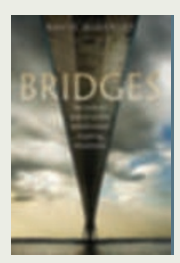

In Bridges (Oxford Univ. Press, 2010), engineer David Blockley sings the praises of spanning structures. In a clear, no-nonsense account, he explains how to 'read' a bridge - its form, design and construction - and how it conducts the forces along its length to generate its strength. He describes what makes a good bridge and tells the stories of past great bridge builders. $\mathrm{He}$ also gives insight into famous failures, such as the Tacoma Narrows bridge collapse in Washington state and London's wobbly Millennium Bridge. bouncing points of laser light off bronze casts of Back (I) and Back (II) demonstrate how Matisse modified the reliefs.

These fresh insights into Matisse's working methods show how science can transform our understanding of art. "Working with the conservators at the Art Institute of Chicago has been a wonderful experience," says
Erdmann, who usually generates computer simulations of fluid dynamics and analyses the microstructure of materials. He hopes that the exhibition will stimulate further collaborations applying advanced image analysis to art conservation.

Josie Glausiusz is a journalist based in New York. e-mail:jg@planetjosie.net

\section{Evidence for RNA origins}

\section{Life From an RNA World: The Ancestor Within \\ by Michael Yarus \\ Harvard University Press: 2010. 208 pp. $\$ 24.95, € 18.95, € 22.50$}

The RNA-world hypothesis proposes that today's DNA-based life forms evolved from earlier ones that were based on much simpler RNA molecules. Although no such RNA-based organism, or ribocyte, has yet been found, biochemist Michael Yarus marshals the theoretical considerations and lab experiments that lend support to this notion for the origin of life.

Life From an RNA World is an unconventional book about RNA. Rather than opening with the central dogma and attendant teachings on molecular biology, Yarus uses evolution as a gateway. He then takes us on a journey through evolutionary time, concentrating on the roles of the various forms of RNA. Although the book reads like a collection of philosophical essays, its author is a proficient guide.

Yarus first describes the basis of Darwinian evolution, in which the "secret is selection". He explains how differences in the sequence of the RNA found in an organism's ribosomes - part of the protein-making machinery of the cell - are used to classify it into one of the three kingdoms of life. He introduces LUCA, the Last Universal Common Ancestor, "behind or before which lies the RNA world".

Various hypotheses about the origin of life are related in the book. One such is an idea that was independently reached by British geneticist J. B. S. Haldane and Russian biochemist Alexander Oparin. They suggested that the chemically reducing environment of the primitive Earth plus energy from ultraviolet light, lightning or other sources could generate several organic molecules. Chemists Stanley Miller and Harold Urey tested this at the University of Chicago in 1952 in their 'primordial soup experiments' that created amino acids from methane, ammonia, hydrogen and water when the mixture was exposed to an electrical discharge.
The writing picks up when Yarus lays out the talents of RNA. As a molecule that is stable, single-stranded and able to form complex structures, it can assume many roles. Ribosomal and transfer RNAs provide the scaffolding to help make proteins and translate the information held in messenger RNA, which itself transcribes the information coded in DNA. The ribonucleotide building blocks that make up RNA are essential for enzyme function, and there are RNAs that have their own catalytic activity, known as ribozymes. Discovered by US molecular biologist Thomas Cech, these can cut themselves out from larger molecules. Other recent discoveries have revealed the existence of small RNAs, including microRNAs, that are intimately involved in controlling gene expression and translating messenger RNA. But the fact that RNA can adopt this vast catalogue of forms is insufficient evidence for a precursor RNA world.

More compelling is the ability of RNA to evolve under selection pressure, as demonstrated in the elegant SELEX experiments done in Larry Gold's lab at the University of Colorado, Boulder. This evolutionary adaptability may be why it is the nucleic acid of choice for the genome of some of the most difficult and changeable pathogens, such as the influenza viruses. It is a key part of the argument that it was RNA that generated subsequent life forms, and that RNAs were a primitive system for making short chains of amino acids - a system that evolved to produce the protein-based structural and metabolic machinery found in organisms today.

Further proof for the primitive RNA world could come from next-generation sequencing platforms that allow deep sampling of nucleicacid populations from microorganisms in exotic locations, such as in deep-sea volcanic vents. But at present, the RNA world remains conjecture, based on powerful observations that this book captures.

Tim Harris is chief technology officer at SAIC-

Frederick, Frederick, Maryland 21702, USA.

e-mail: harristjr@mail.nih.gov 